\title{
PERBEDAAN PENGUASAAN KETERAMPILAN KLINIS VENA PUNKSI DENGAN METODE DEMONSTRASI DAN STUDY GUIDE MENGGUNAKAN DAN TANPA VIDEO
}

\author{
MeizlyAndina ${ }^{1}$, Irfan Hamdani ${ }^{2}$ \\ Fakultas Kedokteran Universitas Muhammadiyah Sumatera Utara \\ meizly_donald@yahoo.com ${ }^{l}$,fanha86@gmail.com ${ }^{2}$
}

\begin{abstract}
Abstrak: Fakultas Kedokteran Universitas Muhammadiyah Sumatera Utara menerapkan kurikulum berbasis kompetensi (KBK) dengan tujuan menghasilkan dokter yang mampu bekerja profesional dalam melayani masyarakat dan mampu mengikuti dan memanfaatkan perkembangan ilmu dan teknologi mutakhir. Salah satu keterampilan klinis yang harus dikuasai seorang dokter adalah vena punksi. Jenis penelitian ini adalah penelitian eksperimental eksperimen semu (quasi experimental) dengan desain "The Statistic Group Comparison" dengan dua kelompok penelitian. Kelompok pertama menggunakan media video (kelompok eksperimen), sedangkan kelompok kedua tidak menggunakan video sebagai media pembelajaran (kelompok kontrol). Sampel penelitian adalah mahasiswa Fakultas Kedokteran Universitas Muhammadiyah angkatan 2014 semester II Grup A. Data yang didapat adalah hasil evaluasi kemampuan keterampilan klinis mahasiswa di dua kelompok (kontrol dan eksperimen) dengan menggunakan alat ukur cek list lembar pengamatan prosedur vena punksi. Berdasarkan hasil uji normalitas Shapiro Wilk didapat bahwa data berdistribusi tidak normal, maka digunakan Mann Whitney Test pada dengan bantuan SPSS. Hasil Mann Whitney Test adalah Sig. 0.28 berarti $\alpha<0,05$, sehingga kesimpulannya adalah ada perbedaan rata-rata kelompok kontrol dan eksperimen. Simpulan, terdapat perbedaan penguasaan keterampilan klinis vena punksi pada mahasiswa semester II dengan metode demonstrasi dan study guide dengan dan tanpa video.
\end{abstract}

Kata kunci: keterampilan klinis, video

\begin{abstract}
Abstrac: Faculty of Medicine, University of North Sumatra Muhammadiyah implement a competency-based curriculum $(C B C)$ with the aim of producing doctors who are able to work professionally in serving the community and is able to follow and take advantage of the development of science and cutting-edge technology. This type of research is experimental research quasi experimental (quasi-experimental) to design "The Statistic Group Comparison" by two research groups. The first group using the medium of video (experimental group), while the second group does not use video as a medium of learning (control group). Samples research is a student of Faculty of Medicine, University of Muhammadiyah force the second half of 2014 the Group A. The data is the result of the evaluation of the ability of clinical skills of students in the two groups (control and experimental) by using a measuring instrument check list observation sheet venous puncture procedure. Based on the results of Shapiro Wilk normality test found that the distribution data is not normal, then used the Mann Whitney Test in SPSS. The results of Mann Whitney Test was Sig. 0:28 means $\alpha<0.05$, so the conclusion is that there is an average difference in control and experimental groups. Conclusion, there are differences in mastery clinical skills venous puncture in the second semester students with the method of demonstration and study guide with and without video.
\end{abstract}

Keywords: clinical skills, video

\section{PENDAHULUAN}

Fakultas Kedokteran Universitas Muhammadiyah Sumatera Utara menerapkan kurikulum berbasis kompetensi (KBK) berpedoman kepada Surat Keputusan Menteri Pendidikan Nasional No. 045/U/2002. Tujuan dari Kurikulum Berbasis Kompetensi ini adalah menghasilkan dokter yang mampu bekerja profesional dalam melayani masyarakat dan mampu mengikuti dan memanfaatkan perkembangan ilmu dan teknologi mutakhir. Sistem pembelajaran yang digunakan adalah metode problem based learning dibagi dalam blok sistem tubuh manusia berdasarkan rapat 
terbatas staf inti Fakultas Kedokteran UMSU penerapan KBK dengan metode PBL dimulai pada tahun akademi 2008/2009 bagi mahasiswa angkatan pertama.

Proses pembelajaran keterampilan klinis dilaksanakan di laboratorium skills lab dengan 5-6 orang mahasiswa dalam kelompok kecil yang dibimbing oleh satu orang instruktur serta dilaksanakan paralel 5 (lima) kelompok kecil. Instruktur keterampilan klinis dasar sebelumnya sudah melalui proses briefing skills dengan expert di bidangnya. Mahasiswa sudah dibekali sebelumnya dengan buku study guide keterampilan klinis dasar yang dibagikan setiap sebelum awal semester. Kegiatan dimulai dengan responsi mahasiswa, membaca do'a, pengantar keterampilan yang akan dilatih serta demonstrasi oleh instruktur dilanjutkan oleh role play setiap mahasiswa. Pada setiap blok yang berjalan, selain kegiatan pelatihan keterampilan klinis dasar yang dibimbing oleh satu orang instruktur di setiap kelompok kecil, terdapat juga kegiatan keterampilan klinis dasar mandiri, dimana dari setiap 5 (lima) kelompok kecil hanya diawasi oleh 2 (dua) orang instruktur. Dari pengalaman saat menjadi pengawas belajar mandiri, seringkali dijumpai teknik keterampilan klinis yang dilatih oleh beberapa instruktur berbeda antara satu dengan yang lainnya walaupun para instruktur telah mengikuti pelaksanaan briefing skills. Hal ini juga didapatkan pada saat menjadi penguji Learning Osce (LO), dimana mahasiswa yang diuji mempraktikkan keterampilan yang tidak sesuai dengan yang seharusnya diajarkan.

Ada dua faktor yang mungkin menjadi penyebab munculnya ketidakseragaman tersebut, yaitu faktor instruktur dan faktor mahasiswa. Instruktur tidak terlalu fokus pada saat briefing sehingga berbeda saat melakukan demonstrasi atau mahasiswa lupa apa teknik yang telah diajarkan, karena hanya diajarkan satu kali demonstrasi oleh instruktur. Penentuan instruktur juga penting, apakah kemampuan, pengetahuan dan pengalamannya sesuai dengan ketrampilan yang akan dilatih. (Corbett, 2008) Masalah ini tentu harus segera diselesaikan, sehingga seluruh mahasiswa mencapai kemampuan dengan keseragaman yang sama di akhir pembelajaran.

Pencapaian kemampuan keterampilan klinik bukan saja hanya di tingkat fakultas, bahkan di seharusnya setiap mahasiswa yang lulus pendidikan dokter di Indonesia telah menguasai keterampilan klinis yang diharapkan. Pada pertemuan Rapat Kerja
Asosiasi Pendidikan Kedokteran dan Kesehatan Muhammadiyah (APKKM) bulan Desember tahun 2014 telah memutuskan untuk melakukan upaya penyerataan dan penyeragaman keterampilan klinis dasar di setiap Fakultas kedokteran Muhammadiyah, sehingga dapat meningkatkan kelulusan OSCE yang merupakan salah satu komponen Ujian Kompetensi Dokter Indonesia. Salah satu keterampilan klinis yang harus dikuasai seorang dokter adalah vena punksi. Vena punksi adalah prosedur pengambilan darah melalui pembuluh darah vena sebagai bahan pemeriksaan laboratorium darah.

Metode dalam rangkaian sistem pembelajaran memegang peran yang sangat penting. Keberhasilan implementasi strategi pembelajaran sangat tergantung pada penggunaan metode pembelajaran, karena suatu strategi pembelajaran hanya mungkin dapat diimplementasikan melalui penggunaan metode pembelajaran. Media audiovisual adalah jenis media yang mengandung unsur suara dan gambar yang bisa dilihat, misalnya rekaman lain sebagainya (Sanjaya, 2007). Video dapat digunakan sebagai alat Bantu mengajar pada berbagai bidang studi. Kemampuan video untuk memanipulasi waktu dan ruang dapat mengajak mahasiswa untuk melihat peristiwa dimana saja walaupun dibatasi dengan ruang kuliah. Objek - objek yang terlalu kecil, terlalu besar, berbahaya atau bahkan tidak dapat dikunjungi oleh mahasiswa, dapat dihadirkan melalui media video (Pribadi dan Putri, 2005). Video dapat menggambarkan suatu objek yang bergerak bersama-sama dengan suara alamiah atau suara yang sesuai. Kemampuan video melukiskan gambar hidup dan suara memberinya daya tarik tersendiri (Arsyad, 2007)

Pembelajaran adalah suatu situasi yang tercipta dari interaksi yang berlangsung antara berbagai faktor (multiple factor) ataupun komponen; guru, siswa (peserta didik), kurikulum, metode, sarana dan media serta komponen lainnya yang diperlukan. Sedangkan tujuan yang diharapkan dari suatu pembelajaran tiada lain berkisar pada analisis tentang bagaimana cara menghilangkan kesenjangan antara perilaku yang ada sekarang dengan perilaku yang diharapkan di masa yang akan datang setelah pembelajaran itu selesai dilaksanakan. (Yasin, 2012)

Kualitas pembelajaran akan bervariasi sesuai dengan variasi dosennya. Dosen adalah manusia, dimana manusia itu unik. Setiap 
manusia memiliki spesisifikasi sendiri. Dengan adanya keunikan itulah tercipta suatu situasi pembelajarannya sendiri-sendiri yang unik pula. Kualitas pembelajaran akan bervariasi sesuai dengan waktu seseorang dosen beraksi. Terdapat perkembangan sistuasi pembelajaran dari seorang guru dari waktu ke waktu, sesuai dengan kondisi psikologis yang melingkupi diri sang dosen. Jadi unsur waktu disini sangat mempengaruhi sistuasi pembelajaran tersebut. Kualitas pembelajaran akan bervariasi sesuai kelompok mahasiswa yang menjadi subjek didik. Maksudnya, suatu kelompok boleh jadi memiliki kecenderungan tertentu dalam upaya pencapaian tujuannya, sehingga mempengaruhi tingkat kecepatan dan intensitas mereka dalam menghadapi proses pembelajaran. Kualitas pembelajaran bervariasi sesuai dengan kurikulum yang disajikan. Kurikulum dalam pengertian ini bukan hanya sekedar materi pelajaran yang telah diatur dan ditetapkan, tetapi juga mencakup metode, strategi, pengelolaan mahasiswa serta aspek lainnya dari kurikulum tersebut. (Yasin, 2012)

Kompetensi inti keterampilan klinis adalah mampu melakukan prosedur klinis yang berkaitan dengan masalah kesehatan dengan menerapkan prinsip keselamatan pasien, keselamatan diri sendiri, dan keselamatan orang lain. Lulusan dokter diharapkan mampu melakukan prosedur diagnosis melalui interpretasi hasil anamnesis, pemeriksaan fisik umum dan khusus sesuai dengan masalah pasien serta menginterpretasi pemeriksaan penunjang dasar dan mengusulkan pemeriksaan penunjang lainnya yang rasional serta mampu melakukan prosedur penatalaksanaan masalah kesehatan secara holistik dan komprehensif.

Keterampilan klinis perlu dilatihkan sejak awal hingga akhir pendidikan dokter secara berkesinambungan. Dalam melaksanakan praktik, lulusan dokter harus menguasai keterampilan klinis untuk mendiagnosis maupun melakukan penatalaksanaan masalah kesehatan. Daftar Keterampilan Klinis ini disusun dari lampiran Daftar Keterampilan Klinis SKDI 201. Data yang terkumpul kemudian dianalisis dan divalidasi dengan metode focus group discussion (FGD) dan nominal group technique (NGT) bersama para dokter dan pakar yang mewakili pemangku kepentingan.

Kemampuan klinis di dalam standar kompetensi ini dapat ditingkatkan melalui pendidikan dan pelatihan berkelanjutan dalam rangka menyerap perkembangan ilmu dan teknologi kedokteran yang diselenggarakan oleh organisasi profesi atau lembaga lain yang diakreditasi oleh organisasi profesi, demikian pula untuk kemampuan klinis lain di luar standar kompetensi dokter yang telah ditetapkan. Pengaturan pendidikan dan pelatihan kedua hal tersebut dibuat oleh organisasi profesi, dalam rangka memenuhi kebutuhan pelayanan kesehatan yang terjangkau dan berkeadilan (pasal 28 UU Praktik Kedokteran no.29/2004).

Daftar Keterampilan Klinis yang disusun pada SKDI bertujuan untuk menjadi acuan bagi institusi pendidikan dokter dalam menyiapkan sumber daya yang berkaitan dengan keterampilan minimal yang harus dikuasai oleh lulusan dokter layanan primer. Daftar Keterampilan Klinis dikelompokkan menurut sistem tubuh manusia untuk menghindari pengulangan. Pada setiap keterampilan klinis ditetapkan tingkat kemampuan yang harus dicapai di akhir pendidikan dokter dengan menggunakan Piramid Miller (knows, knows how, shows, does). (Indonesian Medical Council, 2012)

Media audiovisual adalah jenis media yang mengandung unsur suara dan gambar yang bisa dilihat, misalnya rekaman lain sebagainya (Sanjaya, 2007). Video dapat digunakan sebagai alat Bantu mengajar pada berbagai bidang studi. Kemampuan video untuk memanipulasi waktu dan ruang dapat mengajak mahasiswa untuk melihat peristiwa dimana saja walaupun dibatasi dengan ruang kuliah. Objek - objek yang terlalu kecil, terlalu besar, berbahaya atau bahkan tidak dapat dikunjungi oleh mahasiswa, dapat dihadirkan melalui media video (Pribadi dan Putri, 2005). Video dapat menggambarkan suatu objek yang bergerak bersama-sama dengan suara alamiah atau suara yang sesuai. Kemampuan video melukiskan gambar hidup dan suara memberinya daya tarik tersendiri (Arsyad, 2007)

Pada bidang studi yang banyak mempelajari keterampilan motorik dapat mengandalkan kemampuan video. Melatih keterampilan melakukan kegiatan dengan prosedur tertentu akan terbantu dengan pemanfaatan media video. Dengan kemampuan untuk menyajikan gerakan lambat (slow motion), media video membantu dosen untuk menjelaskan gerakan atau prosedur tertentu dengan lebih rinci. Keterampilan yang dapat dilatih melalui media video tidak hanya berupa keterampilan fisik saja, tetapi juga keterampilan 
interpersonal seperti keterampilan dalam bidang psikologi dan hubungan masyarakat (Pribadi, 2005) Tujuan video ini adalah untuk memberikan hiburan, dokumentasi dan pendidikan. Video dapat menyajikan informasi, memaparkan proses, menjelaskan konsep konsep yang rumit dan mengajarkan keterampilan,menyingkat atau memperpanjang waktu, dan mempengaruhi sikap (Arsyad, 2007)

\section{METODE}

Jenis penelitian ini adalah penelitian eksperimental eksperimen semu (quasi experimental) dengan desain "The Statistic Group Comparison" dengan dua kelompok penelitian (Arikunto, 2002). Kelompok pertama menggunakan media video (kelompok eksperimen), sedangkan kelompok kedua tidak menggunakan video sebagai media pembelajaran (kelompok kontrol). Video yang digunakan adalah video keterampilan klinis dasar prosedur tindakan vena punksi.

Sampel penelitian adalah mahasiswa Fakultas Kedokteran Universitas Muhammadiyah angkatan 2014 semester II Grup A. Kelompok I adalah Grup A1 dan kelompok II adalah Grup A2, dimana masingmasing kelompok terdiri dari 25 orang mahasiswa yang masing-masing dibagi dalam 5 (lima) kelompok kecil.

Penelitian dilaksanakan pada semester genap Tahun Ajaran 2014/2015 Blok Biomedik 3 di Fakultas Kedokteran Universitas Muhammadiyah Sumatera Utara.

Data yang didapat adalah hasil evaluasi kemampuan keterampilan klinis mahasiswa di dua kelompok (kontrol dan eksperimen) dengan menggunakan alat ukur cek list lembar pengamatan prosedur vena punksi. Data kemudian dikumpulkan dan dikelompokkan.

\section{HASIL DAN PEMBAHASAN Hasil}

Penelitian dilakukan di Fakultas Kedokteran Universitas Muhammadiyah Sumater Utara. Dengan mengambil populasi mahasiswa angkatan 2014. Subjek penelitian berjumlah 50 orang dan didapatkan 35 orang $(70 \%)$ laki -laki dan 15 orang $(30 \%)$ perempuan. Subjek penelitian adalah mahasiswa Fakultas Kedokteran Universitas Muhammadiyah Sumatera Utara Angkatan 2014A. Kelompok pertama adalah mahasiswa yang dilatih dengan menggunakan study guide dan demonstrasi sebagai kontrol, sedangkan kelompok kedua menggunakan study guide, demonstrasi dan video sebagai kelompok eksperimen

Masing-masing kelompok eksperimen dan kontrol berjumlah 25 orang. Kelompok eksperimen terdiri dari 18 orang perempuan dan 7 orang laki-laki. Sedangkan kelompok kontrol terdiri dari 17 orang perempuan dan 8 orang laki-laki. Karakteristik yang terkait dengan penelitian adalah proporsi jenis kelamin. Karakteristik proporsi jenis kelamin masingmasing kelompok dianalisis melalui uji Chi square dengan tabel $2 \times 2$ untuk melihat perbedaan karakteristik jenis kelamin antara kelompok intervensi dan kelompok kontrol.

Sebanyak 5 (lima) orang mahasiswa yang dibimbing oleh 1 (satu) orang instruktur di masing-masing skills lab. Kegiatan pada kelompok kontrol dimulai dengan pembacaan doa pembuka dialnjutkan dengan responsi setiap orang mahasiswa. Setelah itu instruktur memberikan penjelasan tentang prosedur yang akan dilatih, kemudian mendemonstrasikan prosedur vena punksi dan dilanjutkan dengan role play setiap peserta.

Kegiatan kemudian diakhiri dengan feedback untuk setiap mahasiswa yang disampaikan oleh instruktur dan kelompok mahasiswa. Kegiatan diakhiri dengan melakukan evaluasi prosedur vena punksi dengan menggunakan lembar pengamatan untuk setiap mahasiswa yang diuji oleh instruktur di setiap ruangan. Setelah semua mahasiswa selesai dievaluasi, kegiatan ditutup dengan pembacaan doa. Sedangkan pada kelompok eksperimen, mahasiswa diberikan video prosedur vena punksi dan mendiskusikan dengan kelompoknya sebelum memulai kegiatan keterampilan klinis dasar seperti yang dijelaskan pada kelompok kontrol.

Berdasarkan analisis, data karakteristik proporsi jenis kelamin memenuhi syarat untuk uji Chi square. Hasil nilai Pearson Chi Square yang didapat adalah $\alpha=0,758$; yang berarti nilai $\alpha>0,05$. Dengan demikian, dapat disimpulkan bahwa tidak ada perbedaan karakteristik proporsi jenis kelamin antara kelompok intervensi dan kelompok kontrol.

Setelah dilakukan analisis terhadap data evaluasi keterampilan, digambarkan bahwa terdapat perbedaan hasil evaluasi keterampilan klinis prosedur vena punksi diantara kelompok kontrol dan eksperimen. Hal ini sesuai dengan hipotesis penelitian dimana metode dengan menggunakan study guide, demonstrasi disertai video memiliki nilai output yang lebih baik. 
Penelitian ini menunjukkan bahwa proses keterampilan klinis dasar di Fakultas Kedokteran Universitas Muhammadiyah Sumatera Utara dapat menggunakan video sebagai media pembelajaran, sehingga output keterampilan yang dihasilkan menjadi lebih baik.

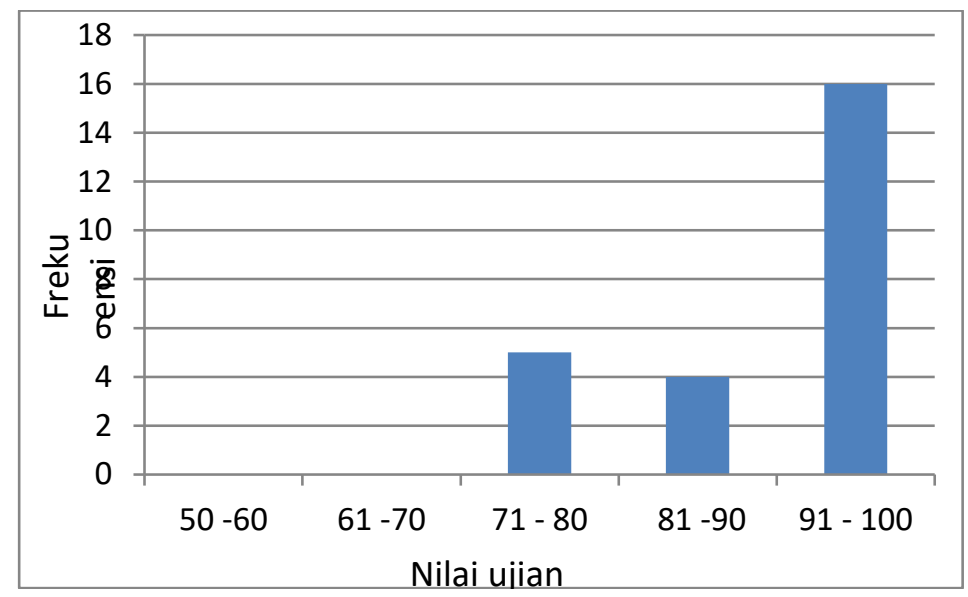

Gambar 1. Distribusi frekuensi nilai evaluasi keterampilan klinis vena punksi dengan metode demonstrasi dan study guide dengan video

Setelah data terkumpul diperlukan adanya analisa data. Berdasarkan data yang diperoleh dari perhitungan hasil uji ShapiroWilk dapat disimpulkan bahwa data rata-rata berdistribusi tidak normal karena memiliki nilai Sig < 0,05 yaitu Sig.0,014 dan 0,000. Sehingga dapat disimpulkan bahwa data hasil evaluasi berdistribusi tidak normal.

Berdasarkan hasil uji normalitas Shapiro Wilk didapat bahwa data berdistribusi tidak normal, maka digunakan Mann Whitney Test pada dengan bantuan SPSS (Statistical Product and Service Solution) or Windows. Mann Whitney Test dilakukan untuk membuktikan adanya perbedaan rata-rata nilai kelompok eksperimen dan kelompok kontrol. Hasil Mann Whitney Test adalah Sig. 0.28 berarti $\alpha<0,05$, sehingga kesimpulannya adalah ada perbedaan rata-rata kelompok kontrol dan eksperimen.

\section{PENUTUP \\ Simpulan}

Simpulan, terdapat perbedaan penguasaan keterampilan klinis vena punksi pada mahasiswa semester II dengan metode demonstrasi dan study guide dengan dan tanpa video. Rerata nilai evaluasi keterampilan klinis vena punksi pada mahasiswa semester II dengan metode demonstrasi dan study guide adalah 84. Rerata nilai evaluasi keterampilan klinis vena punksi pada mahasiswa semester II dengan metode demonstrasi dan study guide dengan video adalah 92.

Berdasarkan hasil penelitian yang didapat, maka diharapkan kegiatan keterampilan klinis dasar Fakultas Kedokteran Universitas Muhammadiyah Sumatera Utara menggunakan video sebagai media pembelajaran skills lab mahasiswa di samping penyediaan study guide dan metode demonstrasi oleh instruktur.

Dalam upaya pembuatan video keterampilan klinis, dibutuhkan staf pengajar yang telah terlatih untuk membuat video yang berkualitas, maka dari itu perlu dukungan dari Fakultas dan Universitas agar kegiatan tersebut terlaksana dengan baik.

\section{DAFTAR PUSTAKA}

Arikunto, S. (2002). Prosedur penelitian.

Arsyad, A. (2007). Media Pembelajaran. Jakarta: Raja Grafindo Persada.

Corbett, E. C. (2008). Recommendations for Preclerkship Clinical Skills Education for Undergraduate Medical Education. Association of American Medical College.

Elizabeth A. Burns, M. M.-C. (2011). Oxford American Handbook of Clinical Examination and Practical Skills. Oxford: Oxford University Press. 
Indonesian Medical Council. (2012). Standar Kompetensi Dokter Indonesia Konsil Kedokteran Indonesia Edisi 2. Jakarta: Konsil Kedokteran Indonesia.

Pribadi, D. P. (2005). Ragam Media. Jakarta: PAU-PPAI

University of Otago, Faculty of Medicine. (2013). Clinical Skills in the Undergraduate
Medical Curriculum An Overview Map. Otago: University of Otago.

Yasin, S. (2012). Metode Belajar dan Pembelajaran yang Efektif. Adabiyah, 1421-6141. 